\title{
Cardiovascular Disease Pattern of Admitted Cases In Medical Ward in 2002 At SGNHC
}

\author{
Dr, D. Sharma -Dr, C. P, Chaulugain Shahid Gangalal National \\ Heart Centre
}

Introduction:

Cardiovascular disease accounts for nearly half of all deaths in developed countries. In developing countries, though communicable diseases still possess the major threat, cardiovascular diseases are rising at an alarming rate. About a quarter of total annual death is caused by cardiovascular disease in developing world. Rheumatic heart disease is considered 'disease of the poor' and is already a big burden in developing countries. But the markedly increased incidence of coronary artery disease in these recent years has alarmed the health care professionals of developing countries. Increasing trend of cardiovascular mortality and morbidity and changing pattern of cardiovascular disease have forced us to look into this matter more seriously.

Since the opening of indoor services in Shahid Gangalal National Heart Centre in May 2000, we have been closely evaluating the admission pattern in medical ward. It has revealed interesting information.

\section{Methods:}

Disease pattern of total 1054 cases, admitted in medical ward from $1^{\text {st }}$ Jan to $31^{\text {st }}$ Dec 2002, were studied retrospectively from the hospital admission book. Proportionate distribution of disease pattern of admitted case was calculated and data compared with figures of previous years.

\section{Results:}

Total 1054 cases, (Mean Age 55 yrs. Range 6-96 yrs.) Including 611 (58\%) male and 443 $(42 \%)$ female were investigated. The number of IHD cases was the highest, altogether 417 , which was $39.5 \%$ of total admission. IHD was respectively followed by RHD (20.8\%) and Essential Hypertension (9.6\%).6.8\% of patients admitted had congenital heart disease, including TOF, VSD, ASD, PDA and coarctation of aorta. $6.5 \%$ were diagnosed as Idiopathic DCM. 2.2\% of patients had COPD-cor pulmonale, $1.9 \%$ patients had Infective endocarditis, among which, 15 had RHD and 5 had CHD as underlying heart problem. Altogether 14 patients $(1.3 \%)$ were admitted with either pericarditis 
or pericardial effusion. Among cardiac arrhythmias, 17 patients (1.6\%) had complete heart block and 8 patients $(0.8 \%)$ had Sinus node dysfunction. 18 patients $(1.8 \%)$ were admitted with yacht tachyarrhythmias like PSVT, VT and Non-Valvular Atrial fibrillation, Relatively not-so-common diseases like Restrictive cardiomyopathy (1). Primary PAH (3, all female), Aortic dissection (1). Aortic aneurysm (2), Takeyasu disease (2), Hypertension with Renal Artery Stenosis (3) were also seen in 2002. Total mortality was $23(\mathrm{M}=8$, $\mathrm{F}=15$ ), which is $2.2 \%$. Majority of the patient, who died in general ward, were suffering from Rheumatic heart disease.

\section{Table1: Disease Distribution of Cases admitted in Medical ward In 2002.}

\begin{tabular}{|l|l|l|l|l|}
\hline Disease & Male & Female & Total & \% \\
\hline Ischemic Heart Disease & 293 & 124 & 417 & 39.5 \\
\hline Rheumatic Heart Disease & 86 & 134 & 220 & 20.8 \\
\hline Hypertension & 59 & 43 & 102 & 9.6 \\
\hline Dilated cardiomyopathy & 44 & 24 & 68 & 6.5 \\
\hline Congenital Heart Disease & 38 & 34 & 72 & 6.8 \\
\hline COPD-Cor pulmonaly & 10 & 13 & 23 & 2.2 \\
\hline Infective Endocarditis & 15 & 5 & 20 & 1.9 \\
\hline Arrhythmia & 25 & 18 & 43 & 4.2 \\
\hline Others & 41 & 48 & 89 & 8.7 \\
\hline Total & 611 & 443 & 1054 & $100 \%$ \\
\hline
\end{tabular}




\section{Discussion:}

Ischemic heart disease was the commonest cause of admission in 2002, leaving Rheumatic heart disease far behind $(39.5 \%$ Vs $20.8 \%)$. Three years back, Rheumatic heart disease was the most common cause of admission in SGNHC, followed by IHD an Hypertension. Last year $26.5 \%$ of admitted patients had IHD and $25.9 \%$ had RHD. This gives us a clear message that the incidence and prevalence rate of IHD is rising at an alarming rate, In-patients records of cardiac admissions in major hospitals also support the impression of on-going epidemic of Is-chemic heart disease in our part of the world, which is already burdened with Rheumatic heart disease. Among 417 IHD patients, about $70 \%$ were male and $30 \%$ female where as in Rheumatic heart disease, there was female preponderance $(60 \%$ vs $40 \%$ ). Prevalence of Hypertension is more common than IHD or RHD in general population but only those with severe Hypertension or Hypertensive Urgency/Emergency are admitted. Hence, Hypertension became the third common cause of admission, male, female ratio being 1.4:1. Among the congenital heart disease, Tetralogy of Fallout was number one cause of admission in medical ward, followed by VSD, ASD and PDA. That is because patients with relatively more common but simpler congenital problems are either managed in OPD or they can easily go for surgical repair. The admission no. of COPD Cor- pulmonaly has reduced from $7 \%$ to $2 \%$ in the last three years.

It is mainly due to encouragement to such patients to receive treatment in general hospitals with strong Respiratory division or Internal medicine department. In conclusion, this study provides the information about the disease pattern and common diseases of cardiovascular system in our country, Is-chemic heart disease, Rheumatic heart disease and Hypertension are the most common cardiovascular diseases in Nepal.

\section{References:}

1. Murray CJL, Lopez AD: The Global Burden of Disease. Cambridge, MA, Harvard School of Public Health, 1996.

2. Limb YR et al; A study on cardiovascular disease pattern of admitted cases in newly emerged National Heart Centre; JNMA, 2001, 41: 284-288.

3. Shrestha N.K.; Coronary Artery Disease in Nepal ; Annual Report 2058 B.S, Shahid Gangalal National Heart Centre; 29-30, 
4. Sharma D. et al: Indoor services in Shahid Gangalal National Heart Centre: Annual Report 2058 B.S. Shahid Gangalal National Heart Centre; 9-12.

5. Eugene Buchenwald (ed.) General Considerations bf Cardiovascular disease; 6 addition, Heart disease 1-18 